\title{
Environment as a Risk Factor for Male Infertility
}

\author{
Luc Multigner $^{1}$ and Alejandro Oliva ${ }^{2}$ \\ ${ }^{1}$ INSERM U 435, Campus de Baulieu, Université Rennes 1, 35042 Rennes, France; \\ ${ }^{2}$ Unidad de Andrologia, Hospital Italiano Garibaldi, 2000 Rosario, Argentina \\ Email: luc.multigner@rennes.inserm.fr
}

Received October 8, 2001; Accepted October 12, 2001; Published October 18, 2001

KEY WORDS: infertility, male infertility, environment, sperm, reproductive hormones, pesticides, solvents

DOMAINS: endocrinology, reproduction, urology, men's health, toxicology, environmental toxicology, environmental policy

Infertility affects $15 \%$ of couples in Western countries. Infertility is defined as the inability to conceive after 1 year of attempts without contraception, but it is not synonymous with sterility. Between 30 and $50 \%$ of infertile couples are infertile due to male reasons, mainly due to sperm production disorders. Although some risk factors, most of which are infectious, have been identified, there is still much uncertainty about the origins of male infertility.

It was first revealed that environmental factors could affect male reproductive function 30 years ago, when pesticide manufacturers and agricultural workers who came into contact with the nematocide, 1-2-dibromo-3-chloropropane, were shown to suffer from severely impaired spermatogenesis, leading to infertility[1,2]. Since this time, many widely used chemicals have been demonstrated to be toxic to male reproductive function in animal models[3]. However, their effects remain largely unexplored in humans, except for those of a few chemicals[4,5,6,7]. Preliminary studies in Belgium[8], U.S.[9] and the Netherlands[10] have provided evidence that occupational exposure to solvents or pesticides may be associated with poor sperm characteristics in infertile men. Awareness has been further stimulated by reports suggesting that sperm production has declined over the last 50 years and that this phenomenon is related to increased amounts of industrial and agricultural pollution[11,12,13].

A study was recently carried out in the Santa Fe and Entre Rios provinces of Argentina[14] . This area, which is one of the most fertile farmland zones in the world, is characterized by intensive agricultural and industrial activity. The study evaluated the relationship between exposure to environmental agents and seminal characteristics, and the concentration of reproductive hormones in male partners of infertile couples attending infertility clinics between 1995 and 1998. For each individual, information was obtained on basic demographic, medical, surgical, reproductive and occupational history, and lifestyle. A complete physical and andrological examination was carried out and men gave a semen specimen and blood sample. They were divided into five groups according to environmental exposure: nonexposed, exposed to pesticides, exposed to solvents, exposed to heat, and exposed to more than one of these.

A multiple logistic regression analysis was used to produce the odds ratio (OR) and the 95\% confidence intervals (95\% CI) for the association between seminal characteristics and exposure variables adjusted for confounding factors. Exposure to pesticides significantly 
increased the risk of having a sperm concentration of below 1 million $/ \mathrm{ml}$ (OR 3.0, 95\% CI 1.27.4), a total number of sperm per ejaculate below 3 million (OR 2.7, 95\% CI 1.1-6.7), less than $50 \%$ motile spermatozoa (OR 4.5, 95\% CI 1.8-11.5), and less than 30\% of spermatozoa with normal morphology (OR 2.1, 95\% CI 1.0-4.8). These associations were higher in men who were frequently exposed than in men who were only occasionally exposed. Exposure to solvents also increased the risk of having poor sperm characteristics, particularly poor sperm motility (OR 3.1, 95\% CI 1.0-9.5). Men exposed to pesticides presented elevated levels of serum oestradiol and an increased oestradiol/testosterone ratio compared to nonexposed men. Men exposed to solvents also had low concentrations of luteinizing hormone.

This study showed that exposure to pesticides and solvents is associated with much lower threshold sperm values than those that are considered to be the limits for male fertility. All of these associations were stronger in men who had never fathered a child (primary infertility) than in men who had previously fathered a child (secondary infertility). This may be because environmental factors worsen the effects of predisposing genetic or medical factors for infertility, as is frequently observed in men with primary infertility. Pesticides and solvents may act directly on the testes, where they target germ cells, Sertoli cells, or Leydig cells[3]. However, other mechanisms should be considered. The increased estrogen/androgen imbalance seen in men exposed to pesticides may be related to the disrupting endocrine activity of some chemicals[15].

Infertility is a major problem for public health. Nowadays, male infertility can be treated in a number of ways, thanks to medically assisted reproduction techniques. However, these expensive approaches raise several ethical questions and their long-term effects on descendants are still poorly known. Due to these difficulties, the best way of answering questions about the risks caused by our environment is to develop real prevention and public health policies. In-depth studies of the environmental risk factors for male infertility must be carried out. However, given the great diversity of chemical substances that men are exposed to on a daily basis, epidemiological studies cannot easily be used to incriminate a given substance. It is therefore also necessary to carry out a detailed toxicological evaluation of these substances to determine whether they are toxic to male reproductive function.

\section{REFERENCES}

1. Whorton, D., Krauss, R.M., Marshall, S., and Milby, T.H. (1977) Infertility in male pesticide workers. Lancet ii, 1259-1261.

2. Slutsky, M., Levin, J.L., and Levy, B.S. (1999) Azoospermia and oligospermia among a large cohort of DBCP applicators in 12 countries. Int. J. Occup. Environ. Health 5, 116-122.

3. Sundaram, K. and Witorsch, R. (1995) Toxic effects on the testes. In Reproductive Toxicology Witorsch, R., Ed. Raven Press, New York. pp. 99-122.

4. Cohn, W.J., Boylan, J.J., Blanke, R.V., Fariss, M.W., Howell, J.R., and Guzelian, P.S. (1978) Treatment of chlordecone (Kepone) toxicity with cholestyramine. Results of a controlled clinical trial. N. Engl. J. Med. 298, 243-248.

5. Wyrobek, A.J., Watchmaker, G., Gordon, L., Wong, K., Moore, D., and Whorton, D. (1981) Sperm shape abnormalities in carbaryl-exposed employees. Environ. Health Perspect. 40, 255-265.

6. $\quad$ Ratcliffe, J.M., Schrader, S.M., Steenland, K., Clapp. D., Turner, T., and Hornung, R. (1987) Semen quality in papaya workers with long term exposure to ethylene dibromide. Br. J. Ind. Med. 44, 317-326.

7. $\quad$ Ratcliffe, J.M., Schrader, S.M., Clapp, D.E., Halperin, W.E., Turner, T.W., and Hornung, R.W. (1989) Semen quality in workers exposed to 2-ethoxyethanol. Br. J. Ind. Med. 46, 399-406.

8. Veulemans, H., Steeno, O., Masschelein, R., and Groeseneken, D. (1993) Exposure to ethylene glycol ethers and spermatogenic disorders in man: a case-control study. Br. J. Ind. Med. 50, 71-78.

9. Bigelow, P.L., Jarrell, J., Young, M.R., Keefe, T.J., and Love, E.J.. (1998) Association of semen quality and occupational factors: comparison of case-control analysis and analysis of continuous variables. Fertil. Steril. 69, $11-18$.

10. Tielemans, E., Burdorf, A., de Velde, E.R., Weber R.F., Van Kooij, R.J., Veulemans H., and Heederick D.J. (1999) Occupationally related exposures and reduced semen quality: a case-control study. Fertil. Steril. 71, 690-696. 
11. Carlsen, E., Giwercman, A., Keiding, N., and Skakkebaek, N. (1992) Evidence for decreasing quality of semen during the past 50 years. Br. Med. J. 305, 609-613.

12. Auger, J., Kunstmann, J., Czyglik, F., and Jouannet, P. (1995) Decline in semen quality among fertile men in Paris during the past 20 years. New Engl. J. Med. 332, 281-285, 1995.

13. Spira, A. and Multigner, L. (1998) Environmental factors and male infertility. The effects of industrial and agricultural pollution on human spermatogenesis. Human Reprod. 13, 2041-2042.

14. Oliva, A., Spira, A., and Multigner L. (2001) Contribution of environmental factors to the risk of male infertility. Human Reprod. 16, 1768-1776.

15. Cheek, A.O. and McLachlan, J.A. (1998) Environmental hormones and the male reproductive system. J. Androl. 19, 5-10.

This article should be referenced as follows:

Multigner, L. and Oliva, A. (2001) Environment as a risk factor for male infertility. TheScientificWorld 1, 576-578.

\section{Handling Editor:}

Lawrence A. Froman, Principal Editor for Endocrinology - a domain of TheScientificWorld. 


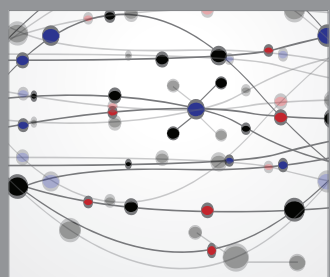

The Scientific World Journal
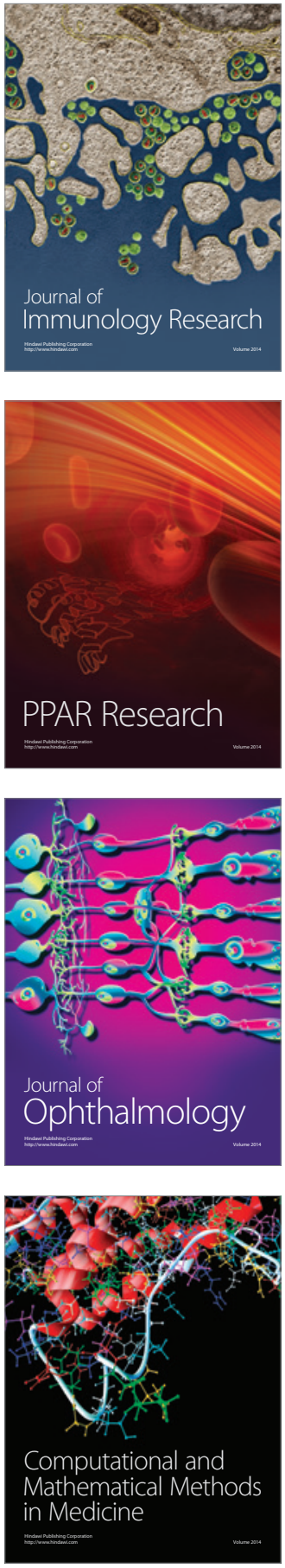

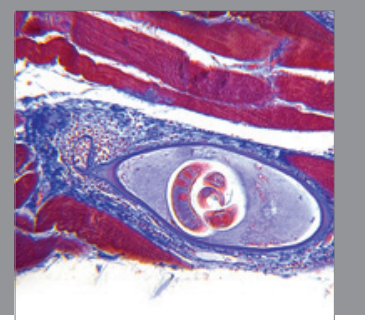

Gastroenterology

Research and Practice
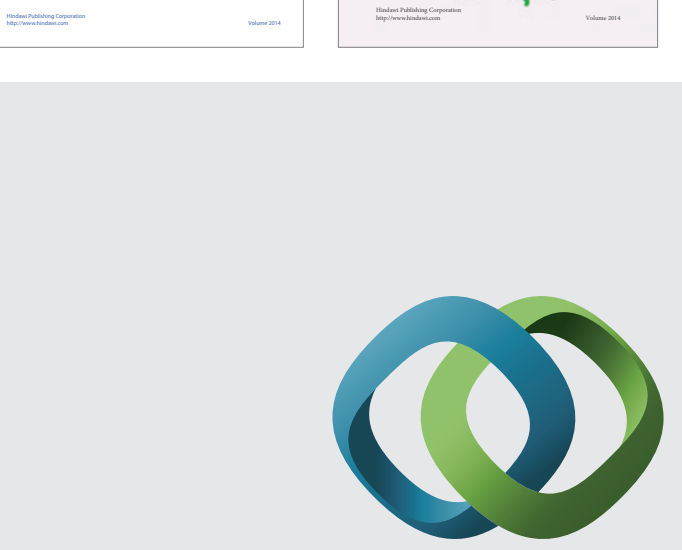

\section{Hindawi}

Submit your manuscripts at

http://www.hindawi.com
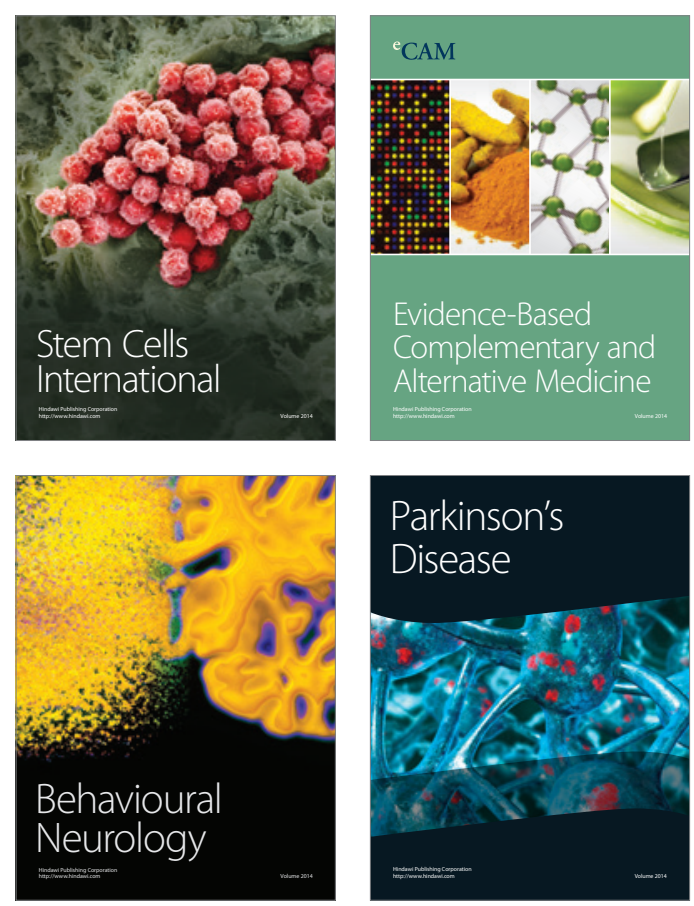

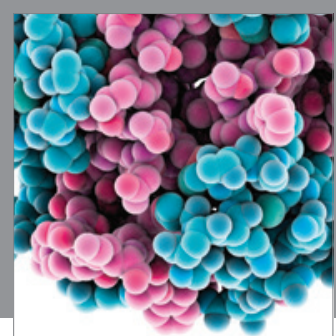

Journal of
Diabetes Research

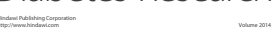

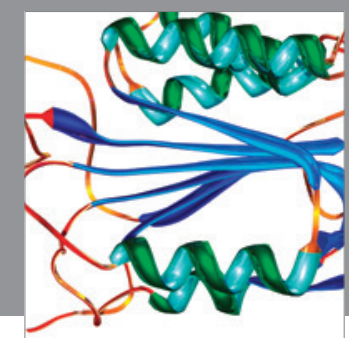

Disease Markers
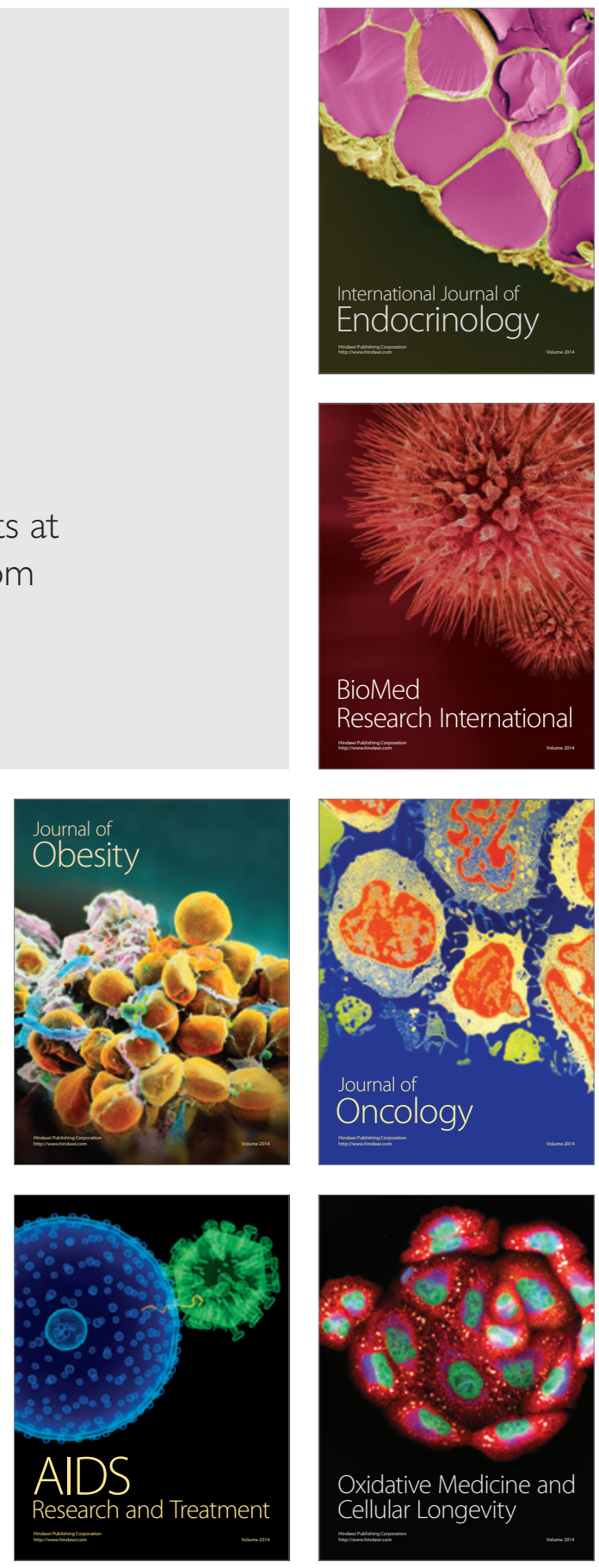